\title{
Clinical assessment of retinopathy post management of pregnancy induced hypertension
}

\section{Rahul Navinchandra Bakhda}

Ex-resident, $\mathrm{M}$ and $\mathrm{J}$ Western Regional Institute of Ophthalmology, B. J. Medical College, Civil Hospital, Asarwa, Ahmedabad, Gujarat, India

Address for the Correspondence:

Dr. Rahul Navinchandra Bakhda, Bakhda Eye Care Clinic, 306 Surya Arcade, 1/12 Panchnath Plot, Near GPO and BOB, Rajkot - 360 001, Gujarat, India. E-mail: bakhdaeyecareclinic@ gmail.com

\begin{tabular}{l} 
Access this article online \\
Website: www.ijmedph.org \\
\hline DOI: $10.4103 / 2230-8598.161516$ \\
Quick response code:
\end{tabular}

Pregnancy induced hypertension (PIH) is a multi-system disorder and common complication occurring during pregnancy responsible for maternal and fetal mortality and morbidity. PIH also exerts its influence on the eye and visual pathways. Common ocular symptoms being blurring of vision, photopsias, scotomas, diplopia and in severe cases blindness. Early diagnosis and treatment through regular antenatal checkup is a key factor to prevent PIH and its complications. The review discusses the after effects of medical management of PIH on the retina.

Key words: Hypertensive disorders of pregnancy, pre-eclampsia, eclampsia, retina, blood pressure, autoregulation

\section{INTRODUCTION}

Pregnancy induced hypertension (PIH) is a hypertensive disorder of pregnancy that occurs after 20 weeks of pregnancy in the absence of other causes of elevated blood pressure (BP) $(140 / 90 \mathrm{mmHg}$ or a rise of $30 \mathrm{mmHg}$ of systolic pressure, or a rise of $15 \mathrm{mmHg}$ of diastolic pressure), taken on two occasions after rest, in combination with generalized edema and/or proteinuria. When there is significant proteinuria it is termed as preeclampsia; seizures or coma as a consequence of PIH is termed as eclampsia. ${ }^{[1]} \mathrm{PIH}$ can have grave consequences for both mother and fetus. Adverse perinatal outcome can be improved by early registration, health education of the couple, regular antenatal checkups and early identification of hypertension and timely decision regarding mode of delivery. Early treatment decreases not only the frequency of hypertensive crisis, but also the rate of neonatal complications. ${ }^{[2]}$ Antihypertensive medications are mainly used to prevent or treat severe hypertension, to prolong pregnancy for as long as safely possible thereby maximizing the gestational age of the infant, and to minimize fetal exposure to medications that may have adverse effects. The complications of PIH extend to involve multiple systems and organs, the eye and visual system are of no exception. Visual complains include blurred vision, photopsias, visual field defects, scotomas, diplopia and in severe cases blindness. ${ }^{[3]}$ Visual symptoms may be the precursor of seizures. ${ }^{[4]}$ Various changes in the fundus and visual problems reported in patients of PIH include spasm and focal/generalized narrowing of retinal arterioles, ${ }^{[5]}$ hemorrhages,${ }^{[5]}$ exudates, ${ }^{[5]}$ peripapillary or focal retinal edema, ${ }^{[5]}$ serous retinal detachment, ${ }^{[6]}$ isolated cases of acute ischemic optic neuropathy, ${ }^{[7]}$ transient blindness, ${ }^{[8]}$ cortical blindness, ${ }^{[9-11]}$ exudative retinal detachment, retinal pigment epithelial lesions, ${ }^{[12]}$ permanent blindness secondary to central retinal artery occlusion ${ }^{[13,14]}$ and optic atrophy. ${ }^{[15,16]}$ Optic atrophy secondary to retinal vascular involvement is unusual but may cause visual impairment. The review discusses the after effects of management of PIH on retina.

Details of clinical assessment of retinopathy post management of PIH is as under.

\section{Papilloedema}

Papilloedema ${ }^{[16]}$ and surrounding retinal edema resolve; leaving an optic disc of near normal appearance within a few weeks; depending upon the severity of disc edema before employing the treatment.

Sometimes it may increase during first few days of treatment after BP reduction has begun, before it begins to clear. 
A grossly swollen disc may not return to normal completely but may retain a permanent blurred outline, even after months or years; consecutive atrophy is rare. Thus, optic nerve involvement may accompany the retinal vascular changes, and optic atrophy can be the end result and cause visual disability. ${ }^{[15,16]}$

\section{Cotton wool spots}

These may increase in size or even new ones appear in first few days after institution of antihypertensive treatment and does not indicate poor prognosis.

Established cotton wool spots ${ }^{[17]}$ pass through a characteristic cycle of events, becoming smaller, duller and sometimes fragmenting before actual fading without trace. During the clearing stage, cotton wool spots may become granular in appearance leading to possible confusion with hard exudates, but these fading cotton wool spots may be distinguished ophthalmoscopically.

The time taken for it to disappear may vary in size of the lesion from 2 weeks about 2 months.

\section{Hemorrhages}

Superficial hemorrhages absorb rapidly with treatment at the same rate to leave normal retina. Larger hemorrhages, if preretinal, take larger time.

Hypertensive patients with flame shaped hemorrhages have a favorable prognosis. It is bright red in color and disappears within 6-8 weeks compared to dot and blot hemorrhages, which is round in shape and dark red in color, of capillary and venous origin and persists for longer period.

\section{Hard exudates}

Especially around macular area take considerably longer time to absorb than cotton wool spots. They commonly become evident and may increase in a number as an acute exudative retinopathy with disc edema, cotton wool spots and hemorrhages begin to subside. However, with continuation of treatment, prolonged observation shows that they disappear, complete resolution take longer than a year.

\section{Arteriolar changes}

As might be expected from their histological nature, are little influenced by BP reduction particularly arterio venous crossing changes and alteration in light reflex. ${ }^{[3,5]}$

Focal or segmental narrowing of arterioles persists unchanged.

Many patients were examined a few days after delivery, when the BP had return to normal, and the formerly constricted arterioles had resumed their normal caliber and the normal ratio. Angiospasm is important for diagnostic as well as a prognostic purpose. Hence, recognition of this condition, together with the institution of adequate hypotensive measures may present the onset of more serious retinopathy and general progression of the illness.

\section{RETINAL DETACHMENT}

Retinal detachment ${ }^{[6,18]}$ is reversible and normal vision should return in three weeks or less. There is a direct relation between ischemic infarcts of choriocapillaries and retinal separation. Choriocapillaries infarction was suggested by chronic pigment epithelial change. ${ }^{[18,19]}$ Choroid vascular insufficiency is the basis for secondary retinal detachments in PIH. Retinal striae may be the first sign, followed by focal accumulation of sub retinal or sub pigment epithelial exudates at the posterior pole. The detachments may progress to involve the entire retina and are usually associated with yellow, white deposits at the level of retinal pigment epithelium. Soon after delivery, spontaneous retinal reattachment occurs and return of vision is complete in almost all cases; despite the development of permanent pigment epithelial alterations-Elschnigs spots. ${ }^{[19]}$ These are nonprogressive pigmentary disturbances if discovered later in life may be mistaken for heredomacular dystrophy or diffuse tapetoretinal dystrophy ${ }^{[12]}$ Cases of optic atrophy following detachment have been reported. Spontaneous vitreous hemorrhage ${ }^{[20]}$ and bilateral retinal neovascularization ${ }^{[21,22]}$ regressing after delivery has been reported in PIH with clotting abnormalities. ${ }^{[23]}$

\section{CENTRAL SEROUS CHORIORETINOPATHY}

Central serous chorioretinopathy $(\mathrm{CSC})^{[24,25]}$ has been reported to develop in the third trimester and resolve spontaneously within 4-8 weeks after delivery with visual function returning back to normal. Majority of the patients develop white presumably fibrinous sub retinal exudates. ${ }^{[25]}$ Most of such patients have a recurrence of CSC in their future pregnancies. The precise etiopathogenesis of CSC is not known.

\section{HYPERTENSIVE OPTIC NEUROPATHY AND REDUCTION OF BLOOD PRESSURE}

There are number of reports indicating inherent danger of precipitous lowering of $\mathrm{BP}$ in patients of malignant hypertension; who besides developing severe neurological and cardiovascular complications may suffer from complete blindness resulting from infarction of optic nerve head. ${ }^{[26]}$

In the presence of micro vascular changes, any sudden lowering of BP may result in severe ischemic results. Auto regulation gets disrupted if the perfusion pressure falls above or below the critical range. There is ample evidence to suggest that if BP rises gradually, the auto regulatory mechanisms show an adaptive phenomenon; range of auto regulation ${ }^{[27,28]}$ shifts to higher levels. Such alterations make the patient less tolerant to low BP and sudden fall at BP in hypertensive patient may cause the perfusion pressure to fall below critical range with disruption of auto regulatory mechanisms and systemic or ocular vascular accidents.

Sudden lowering of BP by aggressive management in these cases cause nonarteritic anterior ischemic optic neuropathy ${ }^{[29]}$ and blindness. In malignant hypertensive patients, BP should be 
lowered gradually to allow auto regulation of blood flow to adapt to falling BP.

\section{CONCLUSIONS}

Pregnancy induced hypertension is a major cause of maternal death and obstetric morbidity. Termination of pregnancy in majority of uncomplicated cases is usually, followed by rapid resolution of retinal changes and visual recovery and in extreme cases with impaired, but useful vision. In rarest cases a certain degree of optic atrophy or permanent macular change causing visual loss remain as lasting disability and on rare counts the visual disability is progressive.

Despite the occurrence of visual loss in PIH, final visual prognosis is good.

Although transient blindness has been reported in patients with eclampsia with current methods of treatment, the present incidence is much lower.

Temporary blindness with subsequent complete visual recovery has been explained on the basis of reversible severe retinal arteriolar spasm.

Optic atrophy secondary to retinal vascular involvement is unusual but may cause visual impairment.

Isolated cases of permanent total blindness as a result of retinal arteriolar occlusion or selective ischemia of optic nerve have been reported in literature.

Visual loss secondary to retinal detachment is usually temporary; with visual recovery occurring within days after delivery.

However, despite spontaneous retinal reattachment, focal pigmentary macular disturbances with some visual impairment may persist.

Cortical blindness associated with cerebral edema and normal fundus is extremely rare and this type of visual loss is reversible. Permanent blindness rarely follows preeclampsia. When it does occur, blindness may be the result of primary ocular and cerebrovascular lesions. ${ }^{[30]}$ Thus in extreme cases there are permanent disturbances in retina showing narrowing of arteriolar caliber, depigmentation of retinal pigment layer, spots of choroid atrophy and black clumps of pigments in macula and partial optic atrophy.

\section{REFERENCES}

1. Cunningham FG, Gant NF, Leveno KJ, Gilstrap LC, Hauth JC, Wenstom KD. Hypertensive disorders in pregnancy. In: Seillis A, Noujaim SR, Davis K, editors. Williams Obstetrics. International Edition. $21^{\text {st }}$ ed. New York: McGraw Hill; 2001. p. 567-618.

2. Kaplan NM. Management of hypertensive emergencies. Lancet 1994;344:1335-8.

3. Hallum AV. Eye changes in hypertensive toxaemia of pregnancy. A study of three hundred cases. JAMA 1936;106:1649-51.
4. Watson DL, Sibai BM, Shaver DC, Dacus JV, Anderson GD. Late postpartum eclampsia: An update. South Med J 1983;76:1487-9.

5. Hallum AV. Changes in retinal arterioles associated with the hypertensions of pregnancy. Arch Ophthal 1947;37:472-90.

6. Clapp CA. Detachment of the retina in eclampsia and toxaemia of pregnancy. Am J Ophthalmol 1919;2:473-85.

7. Beck RW, Gamel JW, Willcourt RJ, Berman G. Acute ischemic optic neuropathy in severe preeclampsia. Am J Ophthalmol 1980;90:342-6.

8. Kesler A, Kaneti H, Kidron D. Transient cortical blindness in preeclampsia with indication of generalized vascular endothelial damage. J Neuroophthalmol 1998;18:163-5.

9. Cunningham FG, Fernandez $\mathrm{CO}$, Hernandez C. Blindness associated with preeclampsia and eclampsia. Am J Obstet Gynecol 1995;172:1291-8.

10. Llovera I, Roit Z, Johnson A, Sherman L. Cortical blindness, a rare complication of pre-eclampsia. J Emerg Med 2005;29:295-7.

11. Moseman CP, Shelton S. Permanent blindness as a complication of pregnancy induced hypertension. Obstet Gynecol 2002;100:943-5.

12. Gass DM, Pautler SE. Toxemia of pregnancy pigment epitheliopathy masquerading as a heredomacular dystrophy. Trans Am Ophthalmol Soc 1985;83:114-30.

13. Rahman I, Saleemi G, Semple D, et al. Pre-eclampsia resulting in central retinal vein occlusion. Eye (Lond) 2006;20:955-7.

14. Hayreh SS. Occlusion of central retinal vessels. $\mathrm{Br} \mathrm{J}$ Ophthalmol 1965;49:626.

15. Trobe JD, Glaser JS, Cassady JC. Optic atrophy. Differential diagnosis by fundus observation alone. Arch Ophthalmol 1980;98:1040-5.

16. Wagener HP. Lesions of the optic nerve and retina in pregnancy. JAMA 1934;103:1910-13.

17. Brown GC, Brown MM, Hiller $\mathrm{T}$, et al. Cotton-wool spots. Retina 1985;5:206-14.

18. Sathish S, Arnold JJ. Bilateral choroidal ischaemia and serous retinal detachment in pre-eclampsia. Clin Experiment Ophthalmol 2000;28:387-90.

19. Fastenberg DM, Fetkenhour CL, Choromolos E, Shoch DE. Choroidal vascular changes in toxemia of pregnancy. Am $J$ Ophthalmol 1980;89:362-8.

20. Forrester JV, Williamsons J, Lee WR. The pathology of vitreous hemorrhage. II. Ultrastructure. Arch Ophthalmol 1979;97:2368-74.

21. Brancato R, Menchini U, Bandello F. Proliferative retinopathy and toxemia of pregnancy. Ann Ophthalmol 1987;19:182-3.

22. Rhee P, Dev S, Mieler WF. The development of choroidal neovascularization in pregnancy. Retina 1999;19:520-4.

23. Leduce $\mathrm{L}$, Wheeler JM, et al. Coagulation profile in severe preeclampsia. J Obstet Gynecol 1992;79:14-8.

24. Chumbley LC, Frank RN. Central serous retinopathy and pregnancy. Am J Ophthalmol 1974;77:158-60.

25. Gass JD. Central serous chorioretinopathy and white subretinal exudation during pregnancy. Arch Ophthalmol 1991;109:677-81.

26. Connolly SE, Gordon KB, Horton JC. Salvage of vision after hypotension-induced ischemic optic neuropathy. Am J Ophthalmol 1994;117:235-42.

27. Bill A. Autonomic nervous control of uveal blood flow. Acta Physiol Scand 1962;56:70-81.

28. Weiter JJ, Schachar RA, Ernest JT. Control of intraocular blood flow. II. Effects of sympathetic tone. Invest Ophthalmol 1973;12:332-4.

29. Hayreh SS, Joos KM, Podhajsky PA, et al. Systemic diseases associated with nonarteritic anterior ischemic optic neuropathy. Am J Ophthalmol 1994;118:766-80.

30. Cipolla MJ. Cerebrovascular function in pregnancy and eclampsia. Hypertension 2007;50:14-24.

How to cite this article: Bakhda RN. Clinical assessment of retinopathy post management of pregnancy induced hypertension. Int J Med Public Health 2015;5:205-7.

Source of Support: Nil, Conflicts of Interest: None declared. 